\title{
The ability of functional mobility tests to identify elderly with recurrent falls
}

\author{
Kumara KCR ${ }^{1}$, De Silva PV ${ }^{2}$, De Silva $\mathbf{U}^{1}$, Lekamwasam $\mathrm{S}^{2}$ \\ ${ }^{\prime}$ Teaching Hospital Karapitiya, Galle, Sri Lanka \\ ${ }^{2}$ Faculty of Medicine, University of Ruhuna, Galle, Sri Lanka \\ Correspondence: Dr K.C.R. Kumara, \\ e-mail: chkottage@yahoo.com
}

\begin{abstract}
Introduction: Falls are common and often a devastating problem among elderly people causing a tremendous amount of morbidity, mortality and use of health care facilities. Prognostic tools are needed to identify elders with an increased risk of falling in order to take preventive actions. Frequently used tools include Timed Up and Go test (TUG), Five times Sit To Stand (5-STS) and Six Meter Walk Test (SMWT). The present study was performed to assess whether the TUG, 5-STS and SMWT were different between elderly fallers and non fallers, and to test their ability to discriminate them.
\end{abstract}

Methods: Study was carried out on hospital patients in a tertiary care hospital in the Southern province. Elderly patients attending medical clinics in this hospital were considered for the selection of study sample. Patients who self reported multiple falls within the previous 12 months were recruited as cases and age and sex matched patients without falls during last 12 months were recruited as controls.

Results: There is no significant difference between the mean durations of SMWT and 5-STS among fallers and non-fallers. However, mean duration for the test TUG was significantly higher among fallers compared to nonfallers. According to the ROC analysis, best TUG cut- off point to identify the fallers was 11.8 seconds which was associated with sensitivity of $80 \%$ and specificity of $60 \%$.

Conclusion: Of the mobility tests examined, TUG provided the best discrimination between multiple fallers and non-fallers. Thus it can be used to identify the patients who are at risk of falls.

\section{Introduction}

Falls are common and often a serious problem among elderly people causing a considerable morbidity, mortality and use of health care facilities. A fall is usually defined as "an event which results in the person coming to rest inadvertently on the ground or other lower level, and other than as a consequence of the following: sustaining a violent blow, loss of consciousness, sudden onset paralysis, an epileptic seizure" (1). According to the previous studies, $28-35 \%$ of community dwelling older people over 64 years of age fall each year and those who are 70 years and older, approximately $32-42 \%$ fall each year (2). The unintentional injuries are the fifth leading cause of death in older people (after cardiovascular disease, cancer, stoke and pulmonary disorders), and falls contribute to $2 / 3$ of these deaths. In United States, about 3/4 of deaths due to falls occur in $13 \%$ of the population aged above 65 . About $40 \%$ of this age group living at home, experience a fall at least once each year and about 1 in 40 of them needs to be hospitalized (3).

When falls are associated with fracture of the proximal femur they carry a high degree of morbidity and mortality. Even minor falls lead to loss of self confidence and low quality of life. This can also have 
significant economic problems because of the cost of inpatient care and also loss of independence and the cost of residential care. Previous studies suggest that about $50 \%$ of patients who live independently before sustaining hip fracture are unable to do so afterwards. Nearly $5-12 \%$ of hip fracture patients discharged to post acute care facility are readmitted to hospital within six weeks. About $5-10 \%$ of patients die within one month, whilst around $20-30 \%$ dies within one year (4). In 1999, the total cost to the UK government for unintentional falls was almost one billion pounds (5).

Prognostic tools are needed to identify individual with an increased risk of falling in order to take preventive actions. Frequently used tools include Timed Up and Go test (TUG), Five times Sit To Stand (5-STS) and Six Meter Walk Test (SMWT). However, most of these tests have not been validated prospectively in large representative samples of elderly people, making their predictive accuracy uncertain $(6,7)$.

The world is aging and in Sri Lanka as in other countries, rapidity of population aging continues. In 1991 elderly population (age 60 and over) was 1.4 million. But in 2021, projected number will be 4.0 million (8). Therefore, total cost for the management of falls and its related morbidity among elderly population would be high in near future. The objective of study was to assess whether the TUG, 5-STS and SMWT were different between elderly fallers and non fallers, and to test their ability to discriminate them.

By evaluating functional mobility tests in our population we will be able to identify the people who are at risk of falling and manage accordingly. Even though there are several studies done in other countries to evaluate functional mobility test among elderly population, not sufficient studies have been done in Sri Lanka $(6,7,9)$.

\section{Methods}

This was a cross-sectional study involving clinic patients in a tertiary care hospital (Teaching hospital Karapitiya) in the Southern province. Elderly patients attending medical clinics in this hospital were considered for the selection of the study sample.
Cases were the elderly (age $>65 \mathrm{yrs}$ ) who had experienced multiple falls (two or more falls) during the previous 12 months. A fall was defined as any event that led to an unplanned, unexpected contact with a supporting surface. Patients with acute illness or injury which impaired their ability to walk or maintain balance were excluded. Controls of the study were selected from the same clinics. They were elders (age $>65 y$ s) who did not experience any falls within previous 12 months. After recruiting the participants were given a demonstration and explanation of each functional mobility test.

1) 5-Sit To Stand test (5-STS): Participants were asked to rise from a standard height $(36 \mathrm{~cm})$ chair without arm rest, five times, as fast as possible with their arms folded. Performance was measured in seconds, as the time from the initial seated position to the final seated position after completing five stands.

2) Six Meter Walk Test (SMWT): Participants were asked to complete a six meter walk test measured in seconds along a corridor at their normal walking speed. A $2 \mathrm{~m}$ approach and a further $2 \mathrm{~m}$ beyond the measured $6 \mathrm{~m}$ distance and ensured that walking speed is constant across the $6 \mathrm{~m}$.

3) Timed Up and Go test (TUG): was the timed performance of getting up from a chair, walking $3 \mathrm{~m}$, turning around and walking back to sit down again.

Descriptive statistical methods were used to describe the participants. Mean time taken to complete each test was compared between fallers and no- fallers. Receiver Operator curve was utilized to determine the cut-off values.

\section{Results}

Table 1 shows the socio-demographic factors of the study participants. Age and gender were similarly distributed among fallers and non-fallers since we selected age and sex matched non-fallers as controls.

Further, there is no significant difference of the distribution of selected vascular diseases among fallers and non-fallers (Table 2). 
Table1: Socio-demographic factors of study participants.

\begin{tabular}{lllll}
\hline Variable & \multicolumn{2}{l}{ Fallers } & \multicolumn{3}{l}{ Non-fallers } \\
\hline Age & Mean 72.26 years & \multicolumn{3}{l}{ Mean 72.26 years } \\
& SD 7.14 & \multicolumn{3}{l}{ SD 7.14 } \\
& Range 65 years to 94 years & Range 65 years to 94 years \\
\hline Gender & Number & Percentage & Number & Percentage \\
Male & 24 & $50 \%$ & 24 & $50 \%$ \\
Marital Status & Number & Percentage & Number & Percentage \\
Married & 40 & $46.5 \%$ & 46 & $53.5 \%$ \\
Unmarried & 7 & 63.6 & 4 & $36.4 \%$ \\
Separated & 1 & $100 \%$ & 0 & $0.0 \%$ \\
\hline
\end{tabular}

Table 2: Distribution of selected major vascular diseases among study participants.

\begin{tabular}{lllll}
\hline Non communicable disease & Faller & \multicolumn{2}{c}{ Non Faller } \\
\cline { 2 - 5 } & Number & Percentage & Number & Percentage \\
\hline Diabetes Mellitus & 21 & $48.8 \%$ & 22 & $51.2 \%$ \\
Ischemic heart disease & 20 & $55.5 \%$ & 16 & $44.5 \%$ \\
Stroke & 10 & $62.5 \%$ & 6 & $37.5 \%$ \\
\hline
\end{tabular}

Fallers spent more time in completing the TGU compared to non-fallers and this difference was significant (Table 3). The differences of other tests between the two groups were not statistically significant.

Table 3: Mean duration for each test by fallers and non-fallers.

\begin{tabular}{|c|c|c|c|}
\hline \multirow[t]{2}{*}{ The Test } & \multicolumn{2}{|c|}{ Mean Duration in seconds } & \multirow[t]{2}{*}{ Difference } \\
\hline & Fallers & Non-Fallers & \\
\hline $\begin{array}{l}\text { SMWT } \\
\text { (Six Meter Walk Test) }\end{array}$ & 10.8 & 9.1 & $\begin{array}{l}\text { T statistic } 1.4 \\
\mathrm{P}=0.15\end{array}$ \\
\hline $\begin{array}{l}\text { 5-STS } \\
\text { (5-Sit To Stand test) }\end{array}$ & 20.0 & 18.5 & $\begin{array}{l}\text { T statistic } 1.09 \\
\mathrm{P}=0.27\end{array}$ \\
\hline $\begin{array}{l}\text { TUG } \\
\text { (Timed Up and Go test) }\end{array}$ & 16.0 & 12.3 & $\begin{array}{l}\text { T statistic } 2.7 \\
\mathrm{P}=0.008\end{array}$ \\
\hline
\end{tabular}


Using the data, faller, non-faller status and the time taken to complete the test TUG, ROC curves were drawn by plotting the sensitivity against 1 - specificity. The point where the curve turn to left was taken as the best cut off point. In this situation, specificity was also considered to minimize the false positives.

Table 4: Area under the ROC curve

\begin{tabular}{llll}
\hline Area & Std. error & Significance & $\mathbf{9 5 \%}$ CI \\
\hline 0.72 & 0.05 & $\mathrm{P}<0.0001$ & Lower 0.62 \\
& & & Upper 0.82 \\
\hline
\end{tabular}

Area under the curve is 0.722 and therefore this test (TUG) has a good ability to distinguish fallers from nonfallers.

Table 5: Selected Coordinates of the curve

\begin{tabular}{lll}
\hline $\begin{array}{l}\text { Positive if greater } \\
\text { than or equal }\end{array}$ & Sensitivity $(\%)$ & Specificity $(\%)$ \\
\hline$* * 11.8$ & $\mathbf{8 0}$ & $\mathbf{6 0}$ \\
12.0 & 78 & 62 \\
12.2 & 76 & 64 \\
12.6 & 74 & 66 \\
13.0 & 72 & 66 \\
\hline
\end{tabular}

According to the coordinates of the curve, best cut off point to identify the fallers was considered to be 11.8 seconds in the test TUG with the sensitivity of $80 \%$ and specificity of $60 \%$.

\section{Discussion}

Falls prevention is an important part of health care of older population. An ability to identify older people who are at risk of future falls is essential for the preventive interventions among high risk individuals. This study assessed the relative ability of three functional mobility tests to predict elderly with recurrent falls.

Multiple fallers performed worse than non fallers in all three tests: TUG, SMWT and 5-STS, when analyzed as continuous variables. However, TUG provided the best discrimination between multiple fallers and non fallers in a scientific analyze with $p$ value of $p=0.008$. This finding is keeping with the recommendation of American and British geriatrics societies to use TUG as the screen test for fallers (10).
We found 11.8 seconds as the optimal cut point for discrimination between multiple fallers and non fallers in this population with $80 \%$ sensitivity and $60 \%$ specificity.

However, it is unlikely that any single functional mobility test will be shown to have excellent predictive value as it is known that the cause of falls are multifactorial with several unrelated to mobility. For example: poor vision, cognitive impairment and cardiovascular conditions lead to falls independent of mobility limitations.

Thus, the identification of a single mobility test for the accurate prediction of falls is a challenge and such test should be used only as initial screens for identifying older people in need of further assessment. 
This study was conducted in a cross-sectional manner and it is a major limitation of this study. Ideal would have been to assess a group of elderly using all three tests and then follow them in a prospective manner. Recurrent fallers can be documented and data can be correlated to the baseline mobility data to identify the best test and the cut-off value. That would have given the best predictive value. Until such data is available the TUG test can be used as an inexpensive screening tool of recurrent falls among elderly in our clinical set ups.

\section{References}

1. Kellogg International Working Group. The prevention of falls in later life. Danish Medical Bulletin 1987; 34(4): 1-24.

2. Sachinyo Yoshida. A Global Report on falls prevention. Www.who.int

3. Rubenstein LZ; Falls in older people: epidemiology, risk factors and strategies for prevention. Age Ageing, $2006 \mathrm{Sep}$; 35 suppl 2: ii37-ii41.

4. Castronuovo E, Pezzottip P, Franzo A, et al. Early and late mortality in elderly patients after hip fracture; a cohort study using administrative health databases in the Lazio region, Italy. BMC Geriatr 2011 Aug; 11: 37. Do1:10.1186/14762318-11-37.
5. Scuffham, S chaplin, R Legood. Incidence and cost of unintentional falls in older people in the United Kindom. JEpidemiol Community Health 2003; 57: 740-4.

6. Schoene D, Wu SM, Mikolaizak AS, Menant JC, Smith ST, Delbaere K, Lord SR. Discriminative ability and predictive validity of the timed up and go test in identifying older people who fall. J Am Geriatr Soc 2013 Feb; 61(2): 202-8.

7. A Tiedemann, H Shimada, C Sherrington, S Murray, S Lord. The comparative ability of eight functional mobility tests for predicting falls in community-dwelling older people. Age and Ageing 2008; 37: 430-5.

8. Healthy Aging www.whosrilanka.org

9. E Nordin, N Lindelo, E Rosendahl, J Jensen, L Lundin. Prognostic validity of the Timed Up-and-Go test, a modified Get-Up-and-Go test, staff's global judgment and fall history in evaluating fall risk in residential care facilities. Age and Ageing 2008; 37: 442-8.

10. Whitney JC, Lord SR, Close JCT. Streamlining assessment and intervention in a falls clinic using the Timed Up and Go Test and Physiological Profile Assessments. Age and Ageing 2005; 34: 567-71. 